\title{
A CONTRIBUIÇÃO DA HERMENÊUTICA PARA O TRABALHO DO MÉDICO RADIOLOGISTA DIANTE DAS TRANSFORMAÇÕES ORIUNDAS DA INOVAÇÃO TECNOLÓGICA
}

\section{The Contribution of Hermeneutics to the Work of the Radiologist in the Face of Transformations Arising from Technological Innovation}

\author{
Thiago Fortes Garcia ${ }^{1}$ \\ Arnaldo Nogaro ${ }^{2}$
}

\begin{abstract}
Resumo: No cenário contemporâneo as máquinas têm substituído o trabalhador. Tal transformação leva a pensar no trabalho do médico radiologista, que necessita hoje de outras habilidades, formas de relacionamento com pessoas e com o conhecimento, sugerindo que somente o conhecimento técnico-instrumental pode não ser mais suficiente, pois a inteligência artificial (IA) figura como uma possível ameaça a este profissional. Contudo, seria uma máquina capaz de substituir o homem na forma de pensar, nas relações interpessoais e em suas análises contextualizadas? Buscando respostas, realizou-se uma pesquisa de natureza teórica, de enfoque qualitativo, com o objetivo geral de compreender e demonstrar a contribuição da hermenêutica para o trabalho do médico radiologista diante das transformações decorrentes da inovação tecnológica. A mente humana precisa ser reorganizada e conduzida a novas formas de pensar. Aposta-se, então, na hermenêutica, principalmente por meio do diálogo, para empoderar o radiologista e assegurar a importância do ser humano no exercício da sua profissão.
\end{abstract}

Palavras-chave: Médico radiologista. Inovação tecnológica. Hermenêutica.

Abstract: In the contemporary scenario, machines have replaced workers. This transformation leads to thinking about the work of the radiologist, who today needs other skills, ways of relating to people and with knowledge, suggesting that technical-instrumental knowledge alone may not be enough anymore, since artificial intelligence is a possible threat to this professional. However, would it be a machine capable of replacing man in way of thinking, in interpersonal relationships and in his contextualized analyzes? In search of answers, a theoretical research was carried out, with a qualitative focus, with the general goal of understanding and demonstrating the contribution of hermeneutics to the work of the radiologist in face of the transformations resulting from technological innovation. The human mind needs to be reorganized and led to new ways of thinking. Thus, we bet on hermeneutics, mainly through dialogue, to empower the radiologist and assure the importance of the human factor in the exercise of his profession.

Keywords: Radiologist. Technological innovation. Hermeneutics.

\footnotetext{
${ }^{1}$ Mestre em Educação - URI. Médico Radiologista. ORCID: https://orcid.org/0000-0001-6663-3319 E-mail: t.gthiagofg@gmail.com.

${ }^{2}$ Doutor em Educação - UFRGS. Mestre em Filosofia. Professor da URI Erechim e do PPGEDU URI Frederico Westphalen. ORCID: https://orcid.org/0000-0003-0517-0511. E-mail: narnaldo@uricer.edu.br.
} 


\section{Introdução}

O cenário decorrente das transformações processadas nos últimos séculos incide diretamente nas diferentes formas de organização da vida, no imaginário social, nos hábitos cotidianos e no pensamento dos sujeitos. A reflexão sobre tudo isso leva necessariamente a pensar sobre a aprendizagem humana e a aquisição e disseminação do conhecimento. Se há a convicção de que a mudança é inconteste, há certa insegurança a respeito das suas implicações futuras, pois há mais perguntas que respostas - e de diferentes naturezas.

O processo de globalização afetou a antiga percepção de mundo. As tecnologias de informação e a comunicação vão moldando e sendo moldadas nesta lógica, convertendo-se no sincronismo de tempos e espaços que, muitas vezes, não se adaptam à nossa mentalidade. $\mathrm{O}$ uso das tecnologias digitais diz respeito à conexão, conectividade e fluxo, implicando outros ambientes e novas formas de pensar, que incidem em diferentes sujeitos e espaços de trabalho, como é o caso da área médica. A difusão tecnológica em massa sustenta-se numa dimensão transcendental, que contribui para determinar o modo de percepção e interação pelo qual conhecemos os objetos, possibilitando que o homem produza, transforme, propague informações, recorrendo a modos de pensar mais subjetivos. Modifica-se, assim, o tipo de competência cognitiva exigida dos sujeitos, que necessitam fazer precisas combinações de símbolos, signos, códigos e mensagens, envolvidos por mediações digitais.

As incidências das transformações tecnológicas são visíveis a olho nu e são sentidas nos espaços de trabalho na forma como este é conduzido e realizado. O trabalho do médico radiologista demanda hoje outras habilidades, formas de relacionamento com pessoas e com o conhecimento, levando a pensar que somente o conhecimento técnico-instrumental não é mais suficiente; a mente humana precisa ser reorganizada e conduzida a novas formas de pensar. Diante de tais mudanças perguntamo-nos: a hermenêutica, como arte da interpretação, pode contribuir com o trabalho do médico radiologista, diante das transformações no mercado de trabalho, decorrentes da inovação tecnológica?

A radiologia iniciou-se e transformou-se com a tecnologia. Destaca-se que os processos relatados com a "descoberta dos raios X", suas aplicações, benefícios, riscos e a proposição de seu ensino nas universidades também estiveram presentes nas demais áreas de atuação do profissional radiologista, que incluem os diferentes métodos de imagem (ultrassom, eletromagnetismo, dentre outros). E este profissional experimentou constante aprendizado técnico e científico, preferencialmente no final do século XX e início do século XXI. Para exemplificar, cita-se que no final da década de 1970 e início dos anos 1980, no Brasil, as residências médicas em radiologia tinham a duração de dois anos e se estudava as aplicações dos raios X. Atualmente, a formação profissional especializada na área tem duração obrigatória de três anos, com o aprendizado de diferentes métodos de obtenção de imagem, dentre eles os raios $\mathrm{X}$.

Nesse contexto, a qualificação técnica, a especialização e a valorização do médico radiologista sempre se mostraram relevantes. Porém, a importância da área de atuação é, por vezes, desconhecida, mesmo por outras especialidades médicas, devido, inclusive, ao fato de que, em algumas das faculdades/universidades de medicina do país e nas Diretrizes Curriculares Nacionais, a cadeira de radiologia não é parte integrante obrigatória, reduzindo a importância desse profissional como agente capaz de especializar e engrandecer a prática médica. 
Estamos cientes, a exemplo do que Gatti (2006) afirma, que a escolha da abordagem de um problema teórico vincula-se primordialmente aos objetivos que se tem, à maneira de se formular o problema e ao alcance pretendido quanto aos resultados. Por isso, fomos em busca de respostas e nos embrenhamos na literatura e nos construtos teóricos vigentes para procurar compreender e demonstrar prováveis contribuições da hermenêutica para o trabalho do médico radiologista diante das transformações no mercado de trabalho, decorrentes da inovação tecnológica.

\section{Hermenêutica: concepções e tarefa}

Sabe-se que a primeira preocupação ou área que a hermenêutica procura desenvolver é certamente a da linguagem e, de modo especial, a da linguagem escrita. Mas o objetivo deste artigo está voltado para o campo da saúde, mais especificamente para o radiologista, a demonstrar como a hermenêutica se torna importante ou fundamental como "arte das interpretações", ou fator preponderante na formação médica, para que o médico possa demonstrar a capacidade diferenciada de análise e interpretação, buscando interfaces e significados que as máquinas são incapazes de atingir ou alcançar. Por isso, é interessante apresentar uma discussão e problematização em torno do que é a hermenêutica, qual sua tarefa e sua contribuição enquanto método de interpretação.

Hermenêutica, no dicionário de filosofia, é definida como qualquer técnica de interpretação. É uma palavra frequentemente usada para indicar a técnica de interpretação da Bíblia. (ABBAGNANO, 2007). Esta concepção é reforçada por Alves (2011), ao manifestar que a hermenêutica, em sua primeira acepção, foi utilizada como intepretação do significado das palavras, como arte de interpretar o que está nos símbolos e, também, interpretação científica baseada na realidade humana.

Grondin (1999) faz referência à hermenêutica enquanto conceito, enquanto "palavra", ter surgido no século XVII, no entanto ele argumenta ser a doutrina que possuía normas e técnicas de interpretação muito mais antigas, desfrutando de uma existência em grande parte invisível como "disciplina auxiliar", no âmbito dos ramos estabelecidos da ciência, os quais se ocupavam explicitamente com a interpretação de textos ou de sinais.

No entendimento de Bleicher (1980), a hermenêutica surgiu esporadicamente e progrediu como teoria da interpretação sempre que houve necessidade de traduzir literatura autorizada em condições que não permitiam o acesso direto a ela, seja em função da distância provocada por espaço ou tempo, seja pelas diferenças em termos de linguagem. Trazer o sentido de um texto à tona exigia um trabalho meticuloso e uma intervenção que acabou sendo assumida pela hermenêutica, que se constituiu em espécie de tecnologia especializada e correta, segundo o autor referido (1980, p. 24), em três níveis: “[...] primeiro, para auxiliar as discussões sobre a linguagem do texto (i. é., o vocabulário e a gramática), dando eventualmente origem à filosofia; segundo, para facilitar a exegese da literatura bíblica; e, terceiro, para guiar a jurisdição."

Recorre-se à "hermenêutica filosófica" para fundamentar alguns pontos de vista teóricos que permitam ancorar alguns posicionamentos que deem sustentação ao que se pretende defender ao longo deste artigo. Ao mesmo tempo, é na filosofia que se encontram os pilares sólidos de onde partir, pois, segundo Flickinger (2000, p. 28), "[...] a 'hermenêutica filosófica' contaria, assim, de modo permanente, com a tensão existente entre essa experiência de caráter ontológico-subjacente sobretudo, como veremos, à linguagem vivida - e as 
pretensões determinadoras, imanentes a toda reflexão."

A opção pela hermenêutica filosófica também representa uma forma de marcar uma posição em favor do conhecimento que supera o historicismo e a visão mítica para instaurar uma posição em favor da racionalidade filosófica representada na linguagem. Daí sua origem, etimologia ou raiz do verbo grego hermeneuein (interpretar) e do substantivo hermeneia (interpretação). Segundo Palmer (1969), este processo de tornar compreensível está explícito nas três vertentes básicas patentes no significado de hermeneuein e hermeneia, no seu uso antigo. As três orientações usando a forma verbal (hermeneuein) para fins explicativos significam: "1) exprimir em voz alta, ou seja, 'dizer'; 2) explicar, como quando explica uma situação, e 3) traduzir, como na tradução de uma língua estrangeira." (PALMER, 1969, p. 24).

Para Rohden (2002), a hermenêutica filosófica, enquanto uma teoria do saber, amplia a razão instrumentalizadora, recoloca e fundamenta o problema do conhecimento. Não se reduz a um instrumento, uma doutrina ou uma corrente filosófica. Constitui e é constituída pelo princípio da experiência hermenêutica.

A hermenêutica filosófica enquanto sistema aberto, de acordo com Rohden (2002), em forma de rede, explicita a filosofia como movimento incessante, constitui os contornos de uma metafísica que lhe é explícita. A metafísica não se limita à identificação de um ou mais princípios, a partir dos quais tudo se reduziria ao inominável, ao incognoscível, que não poderia ser totalmente objetivado. "Ela remete, pois, a uma postura que imbrica ser e saber, que desemboca numa ontologia mais dinâmica e coerente com o saber humano." (ROHDEN, 2002, p. 107).

Os três significados podem ser expressos pelo verbo português "interpretar" e, no entanto, cada um representa um sentido independente e relevante do termo "interpretação". "A interpretação pode, pois, referir-se a três usos bastante diferentes: uma recitação oral, uma explicação racional e uma tradução de outra língua - quer para grego quer para português." (PALMER, 1969, p.25). Restringe-se, aqui, à análise detalhada do sentido de cada uma das orientações para melhor compreendê-las. A primeira é "exprimir", "afirmar" ou "dizer". Isto relaciona-se com a função anunciadora de Hermes: "[...] a sua função não é meramente explicar, mas sim proclamar." (PALMER, 1969, p. 25). A segunda orientação refere-se ao explicar e dá ênfase ao aspecto discursivo da compreensão; aponta para a dimensão explicativa da interpretação, mais do que para a dimensão expressiva. Afinal de contas, as palavras não se limitam a dizer algo; elas explicam, racionalizam e clarificam algo. Pode-se exprimir uma situação sem a explicar; exprimi-la é interpretá-la, mas explicá-la é também uma forma de "interpretação". A terceira orientação faz alusão ao "traduzir". A tradução é uma forma especial do processo básico interpretativo de tornar compreensível. $\mathrm{O}$ ato de traduzir não é uma simples questão mecânica de encontrar sinônimos. "O tradutor é um mediador entre dois mundos diferentes." (PALMER, 1969, p. 37). A tradução exige conhecimento e sensibilidade à cultura em que se está inserido, interpretação do texto e do contexto, por isso que é algo que vai além de um ato mecânico. É ter consciência de que para compreender e interpretar precisa-se estender os horizontes. "A tradução apenas nos torna mais totalmente conscientes do modo como as palavras na realidade moldam nossa visão do mundo, mesmo as nossas percepções.” (PALMER, 1969, p. 37).

Ressalta-se que, como qualquer conceito, o campo da hermenêutica, desde sua origem, vem sendo ressignificado e, segundo Palmer (1969), tem sido definido e interpretado, por ele, de seis maneiras diferentes. Como: 
1) uma teoria da exegese bíblica; 2) uma metodologia filológica geral; 3) uma ciência de toda a compreensão linguística; 4) uma base metodológica dos Geisteswissenschaften; 5) uma fenomenologia da existência e da compreensão existencial; 6) sistemas de interpretação, simultaneamente recolectivos e inconoclásticos, utilizados pelos homens para alcançar significados subjacentes aos mitos e aos símbolos. (PALMER, 1969, p. 43).

Mais que um período da história em que cada uma ocorreu, cada concepção representa uma forma de interpretação de situar a hermenêutica em cada tempo. E neste texto trataremos do sexto aspecto por estar atrelado ao propósito desta escrita: a hermenêutica como um sistema de interpretação: recuperação de sentido versus iconoclasmo. Palmer (1969, p. 53) menciona Ricoeur por este adotar uma definição de hermenêutica que remonta a uma centração na exegese textual, considerando-a o elemento distinto e central na hermenêutica. "A hermenêutica é o sistema pelo qual o significado mais fundo é revelado, para além do conteúdo manifesto." É a busca pelos sentidos expressos e pelos ocultos. É produzir uma exegese que traga à superfície o "não dito", o que não se manifestou, o não latente e que precisa da intervenção do intérprete para que o significado seja produzido.

Pode haver diferenças entre as várias formas de hermenêutica, mas há também muitas semelhanças subjacentes. As diversas orientações na teoria hermenêutica ilustram em si mesmas um princípio hermenêutico: a interpretação é moldada pela questão a partir da qual o intérprete aborda seu tema. (PALMER, 1969). No entender deste mesmo autor (1969, p. 75), é bom que "[...] reconheçamos que as diferentes orientações da hermenêutica não são mais do que tematizações de respostas às questões que os diferentes intérpretes levantaram".

Interpretar é, no fundo, uma necessidade humana, pois é preciso compreender o mundo que está ao redor para poder agir e circular nele. Só é possível estar como humanos e criar possibilidades e estabelecer relações depois de certas condições criadas, e uma delas é que uma cadeia de sentidos esteja estabelecida, para que haja comunicação e para que certos processos sociais ocorram. É por isso que a interpretação e a compreensão são imprescindíveis para que o mundo se torne familiar e o "estranho" o deixe de ser. É o que diz Grondin (1999, p. 49) ao relatar que a interpretação só aparece quando um sentido estranho, ou percebido como estranho, deve ser tornado compreensível. Desta forma,

[...] o interpretar é um modo de tornar compreensível, ou um modo de traduzir um sentido estranho em algo compreensível (não forçosamente em algo familiar, porque coisas não familiares podem, como tais, ser desvendadas pela razão). É com esse processo de interpretação que se ocupa a teoria hermenêutica.

Segundo Gadamer (1997), a interpretação não é, tampouco, um comportamento pedagógico, mas a realização da própria compreensão, que não se cumpre primeiramente só para aqueles em cujo benefício se interpreta, mas também para o próprio intérprete e somente no caráter expresso da interpretação linguística. Graças à sua linguisticidade, toda interpretação contém também uma possível referência a outros. Não existe falar que não envolva simultaneamente o que fala e o seu interlocutor. E isso vale também para o processo hermenêutico. Entretanto, essa referência não determina a realização interpretativa da compreensão ao modo de uma adaptação consciente a uma situação pedagógica, mas essa realização nada mais é que a concreção do próprio sentido. (Grifo do autor). 
A interpretação não é um ato posterior e oportunamente complementar à compreensão, porém, compreender é sempre interpretar, e, por conseguinte, a interpretação é a forma explícita da compreensão; com essa ideia, Gadamer (1997, p. 459) toca no nó górdio da hermenêutica. Ele prossegue afirmando que relacionado com isso está o fato de que "[...] a linguagem e a conceptualidade da interpretação foram reconhecidas como um momento estrutural interno da compreensão, com o que até mesmo o problema da linguagem passa de uma posição ocasional e marginal para o centro da filosofia".

Não há como pensar em hermenêutica sem relação com a linguagem, elas estão profundamente imbricadas, entendendo-se linguagem não somente como a expressão do pensamento, mas como uma presença viva que representa as experiências humanas (BLEICHER, 1980) ou, ainda segundo Gadamer (1997), o medium universal em que se realiza a própria compreensão.

No entendimento de Gadamer (1997), o certo é que o que é linguagem é uma das coisas mais obscuras que há para a reflexão humana. Mas isto não significa que seja inadmissível, que se declare a incapacidade ou nulidade intelectual perante ela. Pode-se superar esse obscurantismo e transpor este limite, construindo pontes de sentido, abrindo canais de comunicação, estabelecendo conexões abertas para novas interpretações, fazendo perguntas, dando respostas.

É importante salientar que o ser humano é um sujeito histórico, situado e relacional. Vive com outros seres semelhantes com quem se relaciona, dialoga, troca ideias e enfrenta os condicionamentos existenciais e históricos. Neste acontecer há processos de mediação fundamentais que precisam ocorrer para que determinados circuitos se realizem; caso contrário, as trocas epistemológicas, culturais, sociais não vão ocorrer. E é nessa intercambialidade que a linguagem funciona como dimensão estratégica. "Vivemos em uma linguagem como em um elemento, como o peixe na água". (ROHDEN, 2002, p. 180). Para este autor procuram-se as palavras, dialoga-se, o indivíduo é e se realiza mais plenamente no e pelo diálogo, e a experiência hermenêutica básica e autêntica é a experiência dialógica. "Esta não trata apenas do diálogo que mantemos com alguém, mas do diálogo que somos e no qual, ao final, nos sentimos mais realizados, mais felizes, mas também numa constituição dialógica da existência." (ROHDEN, 2002, p. 183).

O diálogo é o modo próprio de ser da hermenêutica filosófica, ele não pode ser simplificado, nem reduzido ou equiparado à tradução. Não se trata de uma decodificação de sentido, mas, por depender do diálogo vivo, a busca da verdade, no entender de Flickinger (2010, p. 2), “[...] efetua-se no vaivém das considerações e dos raciocínios dos integrantes, os quais trazem consigo, cada um, a carga de visões do mundo e de sentidos particulares, portanto diferentes. É, porém, justamente a partir dessa carga que nascem as perguntas". A pergunta não só instiga a curiosidade investigativa, criadora, como cria um cenário cheio de novas possibilidades, pois a pergunta rompe com convicções e dogmas.

E por que a hermenêutica precisa estar presente no diálogo ou tornar-se um elemento essencial do diálogo? Porque o diálogo nem sempre é consensual, supõe divergências, embates, contraposições, argumentação, ideias e opiniões diferentes, imergindo dissonâncias. Isso tudo, à primeira vista, para um desconhecido ou desavisado, poderia parecer que inviabilizaria o diálogo, traria a discórdia, o conflito, quando na verdade gera um processo educativo, de aprendizado, de respeito às diferenças, situação em que compreender e interpretar são essenciais para conviver. "O diálogo pode acontecer entre pessoas que possuem opiniões totalmente diferentes. Isso mostra que, onde parece faltar a familiaridade da 
linguagem, mediante a paciência e a tolerância, pode haver compreensão, filosofia". (ROHDEN, 2002, p. 207).

Cada ser humano vive em determinado contexto histórico e isto é determinante quando se trata de falar de compreensão, interpretação, sentido e significado. Só se pode compreender os gêneros de discurso, as falas em sua manifestação real em contexto. Portanto, ao trabalhar com a compreensão e a interpretação e colidir com a questão do sentido, a hermenêutica entra em um debate epistemológico-existencial no qual o homem está mergulhado, que é o perguntar pela razão de ser das coisas, de sua existência, do universo, das grandes indagações. E perguntar, inquirir, sopesar a dúvida, inquietar-se fazem parte do trabalho de quem precisa extrair os sentidos ocultos, interpretar imagens, produzir sentidos, como veremos a seguir.

\section{Prática médica radiológica, hermenêutica e inovação tecnológica}

A prática médica radiológica consiste em interpretar. A leitura de um exame é uma forma de hermenêutica, em que, a partir das imagens obtidas de diversas formas (raios X, ultrassom, ressonância magnética), atribui-se causa e efeito acerca das patologias, guiando os outros profissionais médicos envolvidos ao diagnóstico final. Diante de uma mesma imagem radiológica temos diferentes possibilidades de interpretações. A mesma imagem pode significar mais de uma possibilidade. Por exemplo, em uma criança ou adulto jovem, uma opacidade circular na radiografia de tórax, na ausência das informações clínicas, possivelmente se relaciona mais com uma pneumonia do que com um tumor, ao passo que, em um idoso, a probabilidade de representar uma lesão tumoral aumenta.

Ressalta-se que a organização da radiologia em prol do ensino, voltado para a proteção da vida humana e promoção do melhor diagnóstico das patologias, certamente gerou enorme produção de conhecimento para fazer a diferença no âmbito médico, proporcionando a ampliação e o aprimoramento da interpretação radiológica, que nada mais é do que a prática da hermenêutica aplicada à leitura das imagens na área da saúde.

Foi extremamente relevante o caminho percorrido pela radiologia, desde a descoberta dos raios $\mathrm{X}$ até a aplicação deste na prática médica e a posterior necessidade de ministrar $\mathrm{o}$ ensino da técnica no âmbito acadêmico, visando, especialmente, ao conhecimento da ciência radiológica e de sua importância nos diferentes ramos da medicina, bem como a despertar nos acadêmicos o interesse pela área de atuação.

Assim como a hermenêutica, a radiologia depende da dinâmica do tempo para encontrar a verdade oculta. Neste sentido, a evolução das patologias, a evolução da medicina, e a evolução do conhecimento do próprio profissional que interpreta também traduzem essa descoberta da verdade ao longo do tempo. Destaca-se aqui a importância do profissional radiologista que, com o seu saber, garante um olhar diferenciado, treinado e aprimorado para entender com propriedade o que está diante de seus olhos.

A radiologia, assim como a hermenêutica, também pode se considerar uma arte em que se extraem os sentidos explícitos ou ocultos. Assim como é explícita uma imagem relacionada à fratura deslocada de um osso, uma lesão mamária necessita de interpretação para caracterização e extração do seu potencial maligno, que, aos olhos de quem não tem o conhecimento adequado, pode passar despercebida ou ser mal interpretada.

Seguindo os preceitos da hermenêutica, o conhecimento radiológico e a capacidade interpretativa da verdade que se apresenta em cada imagem dependem não apenas do estudo 
durante a residência médica, mas também das experiências vividas antes e durante o curso de medicina e da residência, bem como da casuística da prática diária e da educação continuada. Educação continuada entendida como processo e um movimento potencializador do pensar que mobilize os sujeitos a produzirem conhecimentos e a criarem outras/novas possibilidades de exercício da prática profissional.

Novamente realizando paralelo com a prática radiológica, para chegar ao diagnóstico final, ou o mais próximo possível deste, o processo de análise (interpretação) das imagens disponíveis é extremamente complexo. Primeiramente, necessita-se conhecer a física da aquisição das imagens, para assim entender como e por que as imagens são geradas e qual será a melhor abordagem para cada método. Depois, é preciso conhecer bem e aliar as questões anatômicas, fisiológicas e patológicas dos órgãos e identificar as estruturas normais e as anormais e contextualizar com as informações clínicas disponíveis, para somente então formular as hipóteses diagnósticas para o caso concreto e tentar chegar o mais perto possível da verdade diagnóstica.

Repisa-se, ainda, que para a interpretação radiológica não basta apenas olhar e descrever as imagens disponíveis, resumindo-se a um mero relator, mas é necessário analisar considerando o contexto próprio de cada paciente para, assim, tornar explícito o que está implícito. A radiologia é a arte de traduzir em palavras e tornar explícitas as condições anatomopatológicas de seus indivíduos. Mesmo quando não é possível afirmar o diagnóstico final, é papel importante do radiologista ampliar o horizonte das patologias possíveis para cada caso, excluindo algumas que, da forma apresentada, sejam pouco prováveis e incluindo e explicitando outras mais prováveis, mas que necessitam ainda de avaliação adicional para melhor caracterização e confirmação diagnóstica. É um processo a ser aprendido num universo educativo, na formação do profissional, no fazer do dia a dia, na práxis do cotidiano, isto é, no permanente fazer e pensar sobre o fazer, reavaliando pontos de vista para redirecioná-los se for necessário.

Segundo Hermann (2002, p.29), o estranhamento é parte essencial da compreensão na postura hermenêutica, pois tal compreensão "[...] não é tanto uma ação da subjetividade, mas um tributo à tradição, uma mediação entre presente e passado, que desde já estabelece o vínculo do intérprete com o mundo". O estranhamento para a prática radiológica também é de extrema importância. A medicina é muito ampla e necessita de constante atualização, porém a anatomia é uma área com poucas alterações. Assim, é mister que o radiologista seja necessariamente um bom conhecedor da anatomia, pois, assim, tudo que o causar estranheza será estudado, documentado e traduzido para os demais médicos de forma anatômica ou patológica.

Após discorrer a respeito da hermenêutica, foi possível construir argumentos que permitiram uma maior clareza de como ela se constitui, seu campo de estudo, sua aplicabilidade, seu fazer e, especialmente, como pode se tornar uma ferramenta cognitiva estratégica num mundo em constante transformação e que adentrou em todas as áreas de atuação profissional, o que não foi diferente com a medicina. As mudanças do mundo do trabalho e da inovação tecnológica criam necessidades para a mente humana, que precisa se reavaliar permanentemente sobre sua capacidade de responder a contento aos desafios com que se depara. Dessa forma, é necessário traçar um panorama deste cenário de inovação para contextualizar a necessidade da hermenêutica no reposicionamento do trabalho do médico radiologista. 
Não há evidência de que na história humana as situações mudaram tão rapidamente quanto nas últimas décadas. O mundo pós-moderno foi afetado, em todas as suas áreas, pelos impactos da Revolução Industrial, gerados, em grande parte, pelos inúmeros avanços tecnológicos causados pela Revolução Científica. Para que se vislumbre um panorama geral do mundo pós-moderno, considerando as mudanças na organização do trabalho e os impactos na educação e na formação do trabalhador, principalmente na área da medicina, é importante percorrer o caminho traçado pela Revolução Científica, nos espaços de tempo pré-moderno e moderno.

O mundo como se conhece foi marcado, no século XXI, pela inter-relação entre as transformações substanciais dos campos da ciência e da tecnologia. "Os últimos 500 anos testemunharam uma série de revoluções de tirar o fôlego. [...] A economia cresceu exponencialmente, e hoje a humanidade desfruta do tipo de riqueza que só existia nos contos de fadas. A ciência e a Revolução Industrial deram à humanidade poderes sobre-humanos e energia praticamente sem limites" (HARARI, 2017, p. 386), que estão sendo utilizados para retroalimentar as engrenagens da humanidade. Um dos fins de utilização dessa energia é o campo do trabalho, que se alia ao da educação para a formação de um trabalhador ideal para a vida no cenário pós-moderno. Nesse contexto, salienta-se a relevância de processos educativos que possam contribuir com a formação de sujeitos cidadãos, humanizados, reflexivos e capazes de análises críticas e de encarar as mudanças rápidas e significativas do contexto local e global.

Por sua vez, as transformações tecnológicas dos últimos séculos - de alcance e velocidade inéditos em nossa história - alteraram o padrão da atividade produtiva e modificaram a natureza do trabalho de uma forma permanente. (HARARI, 2017). Por outro lado, a "[...] cada incorporação de novos modelos do sistema produtivo, exigia-se do trabalhador mais esforço e aprendizagem contínua para adaptação face às novas posturas e competências exigidas" (ROHM; LOPES, 2015, p. 335), e assim as exigências sobre o perfil do trabalhador foram sendo modificadas tão rapidamente quanto as inovações tecnológicas influenciavam as relações de trabalho.

Segundo Gore (2013), a automação industrial em larga escala, até pouco tempo, substituía apenas os operários de posições de chão de fábrica que exerciam tarefas rotineiras, repetitivas e cansativas, porém a introdução de máquinas inteligentes interligadas (e da inteligência artificial) pode colocar em risco outras frentes de trabalho. Mesmo com o desenvolvimento de ferramentas tecnológicas, o ser humano era necessário para operá-las, pois era o único com capacidade cognitiva para fazê-lo (por exemplo: o carro é uma extensão da capacidade de locomoção do homem, mas necessita dele para guiá-lo). Contudo, a extensão tecnológica da capacidade de pensar (aprender e amadurecer) já é uma expectativa e os impactos disso já são vislumbrados, pois se aguarda “[...] a maior de todas as revoluções tecnológicas". (GORE, 2013, p. 43).

Armados de supermáquinas e superprogramas, com acesso irrestrito e veloz à informação disponibilizada na internet, o trabalhador tem, atualmente, um grande desafio: atingir as expectativas e alcançar o perfil do trabalhador ideal atual (TOFFLER; TOFFLER, 2012): uma postura maleável, ágil, aberta a mudanças em curto prazo e passível de assumir riscos, além de maior capacitação, principalmente tecnológica, que suplante tudo o que uma inovação tecnológica possa "pensar".

Neste contexto, no âmbito da radiologia, o desenvolvimento tecnológico, com o uso da inteligência artificial (IA), é um potencial fator transformador do trabalho e do mercado de 
trabalho do profissional médico que atua na área. Com destaque, computadores e sistemas ultratecnológicos, aliados ao sistema capitalista empresarial, podem colocar em xeque um dos pilares da relação médico-paciente, o fator humano, o que, por sua vez, pode comprometer o resultado (diagnóstico). E no que se refere ao campo educacional, especialmente universitário, a forma de lidar com essas transformações refletirá na maneira de educar os futuros profissionais.

Assim, pensar a educação médica hoje torna-se um grande desafio, proposto em discussões para tornar viável uma educação acadêmica contemporânea e vinculada a todas as transformações tecnológicas da atualidade, assumidamente capaz de lidar com a instabilidade e rápida modificação do mundo. O espírito deste tempo está absorvido e contemplado nas Diretrizes Curriculares da medicina (BRASIL, 2014), ao preverem três áreas de formação do médico: I - Atenção à Saúde; II - Gestão em Saúde; e III - Educação em Saúde, dada a necessária articulação entre conhecimentos, habilidades e atitudes requeridas do egresso, para o futuro exercício profissional. O Art. 7, nos seus incisos III e IV, materializa e nos dá uma noção de como isso deve ocorrer.

\footnotetext{
III - aprender interprofissionalmente, com base na reflexão sobre a própria prática e pela troca de saberes com profissionais da área da saúde e outras áreas do conhecimento, para a orientação da identificação e discussão dos problemas, estimulando o aprimoramento da colaboração e da qualidade da atenção à saúde; IV - aprender em situações e ambientes protegidos e controlados, ou em simulações da realidade, identificando e avaliando o erro, como insumo da aprendizagem profissional e organizacional e como suporte pedagógico.
}

Não se pode negar que "[...] as práticas em saúde vêm incorporando um grande e louvável desenvolvimento técnico e científico [...]" (GOMES; REGO, 2011, p. 559), mas o uso dessas tecnologias na prática deve ser acompanhado por conhecimentos teóricos. Assim, na sociedade da pré-modernidade espera-se uma educação que ajude o ser humano a ajustar-se a uma ordem social estabelecida. O século XXI trouxe o desafio de uma educação que sirva como instrumento de aprimoramento da racionalidade (emancipação, cidadania, liberdade, entre outros princípios, estão envolvidas). (RODRIGUES; KUHN, 2013). Bianchetti (2001) corrobora tal entendimento e afirma que além dos conteúdos transmitidos, assimilados, construídos, a expectativa para a educação pós-moderna é que ela atue no campo atitudinal, formando um cidadão disponível para se adequar ao novo mundo do trabalho.

Outrossim, tem-se o cenário contemporâneo (todos os efeitos da rápida transformação da sociedade pelo desenvolvimento de tecnologias e crescimento dos conhecimentos científicos) influenciando a área da saúde no campo da educação, tendo no horizonte a possibilidade de curas improváveis e o surgimento de uma medicina de precisão. Baseando-se em padrões digitais e moleculares dos genes e outras fontes de informações individuais clinicamente relevantes, “[...] muitos especialistas em saúde acreditam que, em breve, será inevitável uma transformação radical na prática da medicina" (GORE, 2013, p. 213), com avanços em praticamente todas as modalidades de atendimento à saúde.

Várias transformações, determinadas pelo avanço das tecnologias aplicadas na área da saúde, já são sentidas no cotidiano das práticas médicas. As tecnologias de produtos, por exemplo, incluindo a indústria farmacêutica, a eletrônica e outras, disponibilizam ferramentas e instrumentos que reformularam o conhecimento, tais como: a cânula arteriovenosa e de instrumentos de depuração do sangue e até mesmo o rim artificial modificaram as expectativas quanto às insuficiências renais crônicas; alguns psicofármacos modificaram as 
atitudes de tratamento e prognóstico de inúmeras doenças crônicas, entre tantos outros exemplos. Mas é necessário que se dê tempo para que os profissionais da área da saúde se adequem às novidades e para que classifiquem as novas tecnologias e os seus usos de acordo com a necessidade, pois não se pode deixar de pensar no encarecimento do atendimento médico - deve-se usar a racionalidade. (STEPKE, 2002). Na mesma linha de raciocínio, o autor (2002, p. 34) afirma que "[...] poderoso equipamento de ressonância magnética nuclear pode satisfazer o orgulho ou a vaidade de um diretor de serviços de saúde, porém administrado de forma inadequada pode ser irrelevante para as necessidades de uma população específica”.

No entendimento de Gomes e Rego (2011, p. 558), deve-se formar profissionais da área da saúde que sejam cidadãos, reflexivos e críticos; há um acordo sobre a necessidade de uma gestão da formação dos profissionais de saúde, realizada por meio de políticas e medidas institucionais. É importante o conhecimento técnico, mas também é de extrema importância sua combinação com o conhecimento crítico, como demonstram as Diretrizes Curriculares da formação médica. (BRASIL, 2014). Em seu Art. $7^{\circ}$, ao referir-se à Educação em Saúde, destaca que o graduando deverá corresponsabilizar-se pela própria formação inicial, continuada e em serviço, autonomia intelectual, responsabilidade social, ao tempo em que se compromete com a formação das futuras gerações de profissionais de saúde, e o estímulo à mobilidade acadêmica e profissional. No inciso primeiro reforça a relevância da formação de conhecimentos sólidos e articulados para a formação da identidade profissional do futuro médico.

Observa-se a urgência - discutida em fóruns no Brasil e no mundo - de uma mudança da formação médica, pois se evidencia que

[...] o novo profissional deverá desenvolver habilidades peculiares à sociedade em que está inserido [...], assegurar capacitação para lidar com aspectos antes não essenciais, como a rapidez da circulação de informações, a utilização das tecnologias de informação e comunicação (TIC) como instrumento de gestão, os processos de educação permanente, a pertinência da ampliação da capacidade da escuta e do acolhimento para a humanização, tendo como permanente linha de ação a visão da integralidade do cuidado em saúde e a aproximação entre capacitação técnica (habilidades psicomotoras, cognitivas e afetivas), ética e compromisso com a cidadania. (GOMES; REGO, 2011, p. 559).

$\mathrm{Na}$ área da radiologia, mais especificamente, busca-se uma maior valorização do profissional radiologista, ou mesmo de sua contribuição para o campo do diagnóstico, a exemplo de uma reforma no currículo dos cursos de medicina, pois a radiologia não é parte do currículo enquanto disciplina isolada, sendo parte integrante de outras (patologia, anatomia, entre outras). Gore (2013) subsidia esta tese, pois, segundo o autor, a área do radiodiagnóstico deve ser profundamente afetada pelo uso da inteligência artificial, que promove redução de erros médicos e precisão no tratamento, aperfeiçoando as habilidades dos radiologistas. Diante de tantos avanços tecnológicos inseridos na radiologia, espera-se que as estratégias pedagógicas possam ser revistas, com maior acesso dos estudantes às práticas do radiodiagnóstico. Igualmente, muito se valoriza e se espera da qualificação profissional, pois "[...] profissionais altamente especializados podem ajudar a produzir inovações e mudanças incrementais" (TOFFLER; TOFFLER, 2012, p. 46), dando notoriedade à educação e à sua importância para o perfil do trabalhador da área da saúde. 


\section{Considerações finais}

Hoje, os avanços tecnológicos, especialmente a inteligência artificial, colocam em xeque a importância, não da especialidade médica em si, mas do profissional que atua neste setor. Percebe-se apreensão e insegurança quanto a essa possível ameaça à profisssão, e há a inquietação a respeito desta incerteza, se a inteligência artificial é realmente capaz de substituir o trabalhador humano. Esta insegurança não é exclusiva de alguns profissionais isolados, mas de toda uma classe, conforme se pode observar com pareceres extremamente atuais de renomados órgãos de classe internacionais, como é o caso do Colégio Americano de Radiologia. Segundo este parecer (ACR; RSNA, 2020), se o objetivo da IA autônoma é remover o médico da interpretação da imagem, o público deve ter certeza de que o algoritmo será tão seguro e eficaz quanto os médicos que ele substitui, o que inclui a capacidade de incorporar o contexto disponível e identificar achados secundários que normalmente seriam identificados durante a interpretação do médico.

Em outras palavras, começa-se a cultivar certo zelo e precaver-se de possíveis imprecisões ou equívocos das máquinas, remetendo à necessidade da presença do especialista para que haja maior confiança e se reduzam possíveis impactos negativos ou erros próprios de um processo automatizado. Nesse sentido, já se observa a versatilidade que o especialista na área necessita ter diante da transformação do mercado de trabalho, embora ainda não fique clara a forma e a intensidade com que as novas tecnologias, especialmente a inteligência artificial, entrarão no mercado futuro. Assim, considerando a perda de espaço nos meios acadêmicos e a "ameaça", ainda que velada, que o profissional da área sofre em relação ao real potencial substitutivo da IA, deve-se buscar, nos campos da filosofia e da educação, uma forma de enfrentamento desta problemática.

Destarte, a hermenêutica surge como resposta ao questionamento de tal problemática, considerando-a um método com probabilidade de auxiliar os profissionais nesse processo de transformação do mercado. A compreensão do potencial da hermenêutica, enquanto método de interpretação, reflexão e crítica revela sua capacidade para empoderar o ser humano frente à máquina, auxiliando-o a se reinventar, a encontrar formas de pensar, interpretar, dialogar, que o diferencie desses artefatos tecnológicos. Nesse contexto, acredita-se que as respostas foram alcançadas com êxito, vislumbrando, hipoteticamente, que novas frentes de pesquisa e entendimento possam ser estendidas para as demais áreas de atuação e campos de trabalho.

Dessa forma, embora o poderio tecnológico das máquinas assuste e cause incertezas e inseguranças, tais máquinas continuarão sendo máquinas enquanto o homem continuará sendo homem. As relações já construídas e que virão a ser necessariamente constituídas só poderão ser feitas com base na confiança e no diálogo. A capacidade de observar, descrever e fazer conexões pontuais (dentro dos bancos de dados virtuais) é fato que as máquinas serão capazes. $\mathrm{O}$ que se percebe, ao longo deste trabalho, é que todos estes aspectos irão necessitar de tradução.

Compreende-se, afinal, que a hermenêutica, como ferramenta de estudo e análise, em sua divisão por Palmer (1969), tem pelo menos três orientações básicas e, nesse sentido, as máquinas podem "exprimir" e "dizer", mas embora possam tentar, poderão ter dificuldade de alcançar efetivamente o entendimento de "traduzir". Os limites do contexto e das relações do diálogo, a princípio, apenas humanos podem alcançar.

O poder do diálogo, de construção da relação de confiança e credibilidade, que é possível por meio da compreensão hermenêutica, é a chave necessária para apoiar e fortalecer a prática médica radiológica e para a educação em saúde como estratégias para preparar ações 
e intervenções em saúde preventiva fundadas no diálogo propositivo com vistas ao cuidado humano. A comunicação, por meio de linguagem verbal e não verbal, com usuários, familiares, comunidades, demais médicos e com outros membros das equipes profissionais, com empatia, sensibilidade e interesse, preservando a confidencialidade, a compreensão, a autonomia e a segurança da pessoa sob cuidado, são constituintes essenciais da atenção e promoção da saúde integral do ser humano.

O fazer do médico, especialmente do radiologista, está imbricado com as transformações profundas, recentes e meteóricas que ocorreram nas últimas décadas. Ao longo desta reflexão foi possível demonstrar e compreender que o trabalho, ao longo do tempo, em sua forma, modos e dinâmica, sofreu transformações multifacetadas que repercutiram na vida pessoal e profissional do ser humano. E os trabalhadores são desafiados a enfrentá-las. Logo, a compreensão do cenário contemporâneo e - por que não? - dos anseios futuros clarifica os caminhos a serem trilhados e traz esperança no enfrentamento e reposicionamento profissional, partindo-se da perspectiva que muitas das avançadas tecnologias, em determinados aspectos, têm como imprescindível o ser humano para operacionalizá-las, aperfeiçoá-las ou acompanhá-las para que estejam em benefício do próprio ser humano.

O estudo da hermenêutica, aliado com as transformações do mundo do trabalho, em um âmbito geral, possibilitou uma melhor compreensão e ressincronização entre a mente e o trabalho. Compreendeu-se que o alcance da mente humana e das relações entre pessoas são frutos de um diálogo profícuo entre quem necessita de ajuda (paciente) e o profissional (médico), que possui conhecimento e mecanismos possíveis de serem postos ao seu alcance na solução dos problemas trazidos a ele.

A automação tecnológica é um caminho sem volta, mas a forma e a segurança com que ela será apresentada para aplicação no uso cotidiano é tarefa também desafiadora. Preza-se pela cooperação homem-máquina e não pela substituição do homem pela máquina, devendo ambos atuar como um time, coordenado pelo homem. Aos médicos especialistas cabe papel ativo dentro deste contexto, especialmente na regulamentação da inserção da inteligência artificial na prática, para garantir segurança diagnóstica e confiabilidade, bem como para assegurar que o fator humano seja parte essencial na relação homem-máquina para a condução e contextualização do caso concreto, com a atenção e o cuidado que cada vida necessita.

\section{Referências}

ABBAGNANO, Nicola. Dicionário de filosofia. São Paulo: Martins Fontes, 2007.

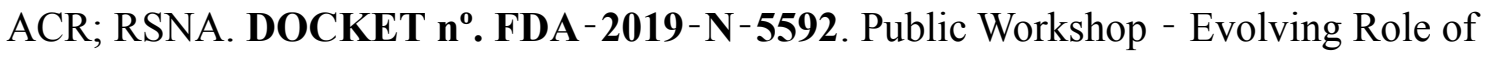
Artificial Intelligence in Radiological Imaging. Comments of the American College of Radiology. June 30, 2020.

ALVES, Marcos Alexandre. Da hermenêutica filosófica à hermenêutica da educação. Acta Scientiarum Education, Maringá, v. 33, n. 1, p. 17-28, 2011.

BIANCHETTI, Lucídio. Da chave de fenda ao laptop. Tecnologia digital e novas qualificações: desafios à educação. Petrópolis/RJ: Vozes, 2001. 
BLEICHER, Josef. Hermenêutica contemporânea. Lisboa: Edições 70, 1980.

BRASIL. Ministério da Educação. Conselho Nacional de Educação. Câmara de Educação Superior. Resolução no 3, de 20 de junho de 2014. Disponível em:

http://portal.mec.gov.br/index.php?option=com_docman\&view=download\&alias=15874-rces 003-14\&category_slug=junho-2014-pdf\&Itemid=30192 Acesso em: Julho de 2020.

FLICKINGER, Hans-Georg. Da experiência da arte à hermenêutica filosófica. In:

ALMEIDA, Custódio Luí Silva. de; FLICKINGER, Hans; ROHDEN, Luiz. Hermenêutica filosófica: nas trilhas de Hans-Georg Gadamer. Porto Alegre: PUCRS, 2000.

FLICKINGER, Hans-Georg. A caminho de uma pedagogia hermenêutica. Campinas/SP: Autores Associados, 2010.

GADAMER, Hans-Georg. Verdade e método: traços fundamentais de uma hermenêutica filosófica. Petrópolis/RJ: Vozes, 1997.

GATTI, Bernardete. Pesquisar em educação: considerações sobre alguns pontos-chave.

Diálogo Educacional, Curitiba, v. 6, n. 19, p. 25-35, set./dez. 2006.

GOMES, Andréia Patrícia; REGO, Sergio. Transformação da Educação Médica: é possível formar um novo médico a partir de mudanças no método de ensino-aprendizagem? Revista Brasileira de Educação Médica, v. 35, n. 4, p. 557-566, 2011.

GOMES, A. P.; REGO, S. Transformação da Educação Médica: é possível formar um novo médico a partir de mudanças no método de ensino-aprendizagem? Revista Brasileira de Educação Médica, v. 35, n. 4, p. 557-566, 2011.

GORE, Al. O futuro. São Paulo: HSM, 2013.

GRONDIN, Jean. Introdução à hermenêutica. São Leopoldo: Unisinos, 1999.

HARARI, Y. N. Sapiens: uma breve história da humanidade. 24. ed. Porto Alegre: L\&PM, 2017.

HERMANN, Nadja. Hermenêutica e Educação. O que você precisa saber sobre. Rio de Janeiro: DP\&A, 2002.

PALMER, Richard. Hermenêutica. Lisboa: Edições 70, 1969.

RODRIGUES, D. B.; KUHN, Martin. Educação e a possibilidade de construção de uma racionalidade contra-hegemônica. In: ANDRADE, Elisabete; ANDRIOLI, Líria; FRANTZ, Walter. Educação no contexto da Globalização. Reflexões a partir de diferentes olhares. Ijuí: Ed. Unijuí, 2013, p. 109-137. 
ROHDEN, Luiz. Hermenêutica filosófica: entre a linguagem da experiência e a experiência da linguagem. São Leopoldo: Unisinos, 2002.

ROHM, Ricardo Henry Dias; LOPES, Natália Fonseca. O novo sentido do trabalho para o sujeito pós-moderno: uma abordagem crítica. Cad. EBAPE.BR, Rio de Janeiro, v. 13, n. 2, p. 332-345, abr./jun. 2015.

STEPKE, Fernando Lolas. Aspectos de uma relação. Tradução de: Gilmar Saint Clair Ribeiro. São Paulo: Loyola, 2002.

TOFFLER, Alvin.; TOFFLER, Heide. O futuro do capitalismo. A economia do conhecimento e o significado da riqueza no século XXI. São Paulo: Saraiva, 2012.

Recebido em setembro de 2020.

Aprovado em maio de 2021. 